\title{
Fluorescent SiC for white light-emitting diodes
}

Ou, Haiyan; Ou, Yiyu; Kamiyama, S.; Kaiser, M.; Wellmann, P.; Linnarsson, M. K.; Jokubavicius, V.; Yakimova, R.; Syvajarvi, M.

Published in:

ACP Technical Digest

Publication date:

2012

Document Version

Publisher's PDF, also known as Version of record

Link back to DTU Orbit

Citation (APA):

Ou, H., Ou, Y., Kamiyama, S., Kaiser, M., Wellmann, P., Linnarsson, M. K., Jokubavicius, V., Yakimova, R., \& Syvajarvi, M. (2012). Fluorescent SiC for white light-emitting diodes. In ACP Technical Digest (pp. JS4F.1). Optical Society of America.

\section{General rights}

Copyright and moral rights for the publications made accessible in the public portal are retained by the authors and/or other copyright owners and it is a condition of accessing publications that users recognise and abide by the legal requirements associated with these rights.

- Users may download and print one copy of any publication from the public portal for the purpose of private study or research.

- You may not further distribute the material or use it for any profit-making activity or commercial gain

- You may freely distribute the URL identifying the publication in the public portal

If you believe that this document breaches copyright please contact us providing details, and we will remove access to the work immediately and investigate your claim. 


\title{
Fluorescent SiC for white light-emitting diodes
}

\author{
H. Ou ${ }^{1}$ Y. Ou ${ }^{1}$, S Kamiyama ${ }^{2}$, M. Kaiser ${ }^{3}$ P. Wellmann ${ }^{3}$, M. K. Linnarsson ${ }^{4}$, V. Jokubavicius ${ }^{5}$ \\ R. Yakimova ${ }^{5}$, M. Syväjärvi ${ }^{5}$ \\ ${ }^{1}$ Department of Photonics Engineering, Technical University of Denmark, DK-2800, Lyngby, Denmark \\ ${ }^{2}$ Department of Materials Science and Engineering, Meijo University, 1-501 Shiogamaguchi, Tenpaku-ku, Nagoya 468-8502, Japan \\ ${ }^{3}$ Materials of Electronics Energy Technology, University of Erlangen-Nuremberg, D-91058, Erlangen, Germany \\ ${ }^{4}$ School of Information and Communication Technology, KTH Royal Institute of Technology, SE-16440, Kista, Sweden \\ ${ }^{5}$ Department of Physics, Chemistry and Biology, Linköping University, SE-58183, Linköping, Sweden \\ haou@fotonik.dtu.dk
}

\begin{abstract}
The strong photoluminescence from f-SiC was achieved after the optimization of the B and $\mathrm{N}$ concentrations. Surface nanostructures were successfully applied to enhance the extraction efficiency. $\mathrm{f}-\mathrm{SiC}$ is a promising wavelength convertor for white LEDs.

OCIS codes: (230.3670) Light-emitting diodes; (160.2540) Fluorescent and luminescent materials
\end{abstract}

\section{Introduction}

Light-emitting diodes (LEDs) have attracted renewed interest in the past decades with the appearance of the world's first efficient blue-emitting GaN LED, for the reason that it could make all-solid-state lighting for large-scale energy saving. Compared with the traditional incandescent and fluorescent light sources, LEDs have longer lifetime, higher overall efficiency, as well as better technical functionality for many new lighting applications. Driven by energy saving and further $\mathrm{CO}_{2}$ emission reduction, high brightness LEDs, as a GREEN light source, represents a multibillion market that is predicted to grow to $\$ 12$ billion by 2013 globally.

Currently, most commercial white LEDs are made by mixing yellow color, converted by the phosphors from blue, and the rest blue color from the blue-emitting diodes. But phosphors degraded much faster than the LED chips, leading to the white LEDs turning blue over time. Recently, fluorescent $\mathrm{SiC}$ has also been approved as an ideal wavelength converter for white LEDs because it has better color rendering ability and long life time [1].

\section{Experiments}

The boron $(\mathrm{B})$ and nitrogen $(\mathrm{N})$ co-doped 6H-SiC epilayers were grown on 6H-SiC (0001) substrates having 1.4 degree off-orientation in the $<11 \overline{2} 0>$ direction by the fast sublimation growth process [2] at temperature of $1725^{\circ} \mathrm{C}$. The growth process is driven by a temperature gradient created between the source, in a form of polycrystalline $\mathrm{SiC}$ plate, and the substrate. B was introduced into the epilayers by co-doping from the source and $\mathrm{N}$ incorporation was controlled by adjusting $\mathrm{N}_{2}$ gas pressure during the growth.

The $6 \mathrm{H}-\mathrm{SiC}$ epilayer codoped with $\mathrm{B}$ and $\mathrm{N}$ has strong fluorescence, so called fluoresecent $\mathrm{SiC}(\mathrm{f}-\mathrm{SiC})$, and its photoluminescence (PL) measurements were realized by using an Olympus reflected fluorescence system microscope, a $377 \mathrm{~nm}$ diode laser as excitation source (focused by a 20X objective), and an Instrument System CAS 140B spectrometer at room temperature.

To enhance the extraction efficiency of the f-SiC, cone-shaped antireflection nanostructures (ARS) are fabricated on the surface of f-SiC epilayers. A positive resist layer was first spin-coated on the 6H-SiC sample and then prebaked. The designed mask pattern was transferred to the resist coating by applying the e-beam lithography. After the development, a hard mask layer was deposited on the patterned resist with a subsequent lift-off process. The dotshaped pattern was then obtained on the hard mask. The dry etching process using $\mathrm{SF}_{6}$ and $\mathrm{O}_{2}$ precursors was carried out in the reactive-ion etching system.

The surface reflectance of the bare and ARS SiC samples were measured from 390 to $785 \mathrm{~nm}$ by a goniometer system at a measured angle of 6 degrees, where 0 degree is the direction normal to the sample surface. The angleresolved photoluminescence spectra were also acquired by the same goniometer system. The $377 \mathrm{~nm}$ diode laser was used as the excitation source which was normal to the sample backside and the detected emission angle varied from 16 to 80 degrees.

The scanning electron microscope (SEM) image was acquired by field-emission SEM Zeiss.

\section{Results and discussions}


High quality single crystalline $6 \mathrm{H}$-SiC epilayers co-doped with $\mathrm{B}$ abd $\mathrm{N}$ have been demonstrated after the characterization of tranmission electron microscopy, lifetime etc.[2]. To investigate the optimized dopant concentrations of $\mathrm{N}$ and $\mathrm{B}$, five samples with varied $\mathrm{N}$ and $\mathrm{B}$ concentrations were studied. The atomic dopant concentrations measured by secondary ion mass spectrometry (SIMS) are listed in Table 1.

Table 1. Dopant concentrations and normalized PL peak intensities of the samples
\begin{tabular}{|l|l|l|l|}
\hline Sample & $\begin{array}{l}\text { B concentration } \\
{\left[\mathrm{cm}^{-3}\right]}\end{array}$ & $\begin{array}{l}\text { N concentration } \\
{\left[\mathrm{cm}^{-3}\right]}\end{array}$ & $\begin{array}{l}\text { PL peak intensity } \\
{[\text { Normalized to sample d] }}\end{array}$ \\
\hline a & $8.0 \times 10^{18}$ & $4.0 \times 10^{16}$ & $0.0 \%$ \\
\hline b & $6.9 \times 10^{18}$ & $3.2 \times 10^{18}$ & $6.6 \%$ \\
\hline c & $6.9 \times 10^{18}$ & $6.0 \times 10^{18}$ & $8.3 \%$ \\
\hline d & $4.4 \times 10^{18}$ & $9.0 \times 10^{18}$ & $100 \%$ \\
\hline e & $5.2 \times 10^{18}$ & $9.2 \times 10^{18}$ & $77.1 \%$ \\
\hline
\end{tabular}

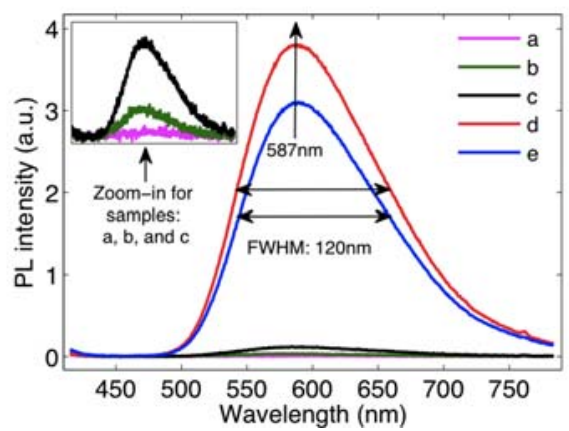

Fig. 1. Measured PL spectra of $B-N$ doped $6 H$-SiC samples (inset: zoom-in for sample $a, b$, and c), same peak wavelength at $587 \mathrm{~nm}$ and FWHM of $120 \mathrm{~nm}$ were observed in all the spectra.

Their corresponding PL spectra are shown in Fig. 1. All samples show PL emission peak at 587nm and FWHM of 120nm. As N concentration increases from sample a to sample d, the emission intensity increases as well. Sample $\mathrm{d}$ has the strongest PL emission. Then the emission intensity drops as the $\mathrm{N}$ concentration increases further. The detailed physical analysis of the relationship between the emission intensity and dopant concentration could be found [3].

Bare and ARS samples are compared in terms of reflectance, spatial emission distribution and angle-resolved PL and the results are shown in Fig. 2. An oblique-view SEM image of the ARS pattern is shown in the inset of Fig. 2(a). The cone-shaped ARS structure has base diameter of $250 \mathrm{~nm}$, pitch of $350 \mathrm{~nm}$, and height of $1.4 \mu \mathrm{m}$. The reflectance spectra of bare sample and ARS structure are shown in Fig. 2(a). It is seen that the surface reflection is effectively suppressed by applying the SiC ARS. The average reflectance over the measured spectral range decreased from $20.5 \%$ to $1.0 \%$ and the minimum reflectance close to 0 was observed at around $400 \mathrm{~nm}$ for the ARS SiC sample. Fig. 2(b) shows the spatial emission patterns for both samples. It can be seen that the luminescence intensity for ARS sample increased at all emission angles with a well preserved spatial emission pattern. It is also found that the luminescence intensity was enhanced by more than $91 \%$ in a very large emission angle range (up to 70 degree). From Fig. 2(c), it is seen that the luminescence intensity of the bare SiC decreases together with a blue shift of the peak wavelength as the emission angle increases from 20 to 70 degree, which could be attributed to the Fabry-Pérot microcavity interference effect. In Fig. 2(d), the peak wavelength remains the same which is due to the elimination of the Fabry-Pérot microcavity interference effect by introducing the ARS on the SiC surface.

To reduce the cost of ARS fabrication, self-assembled nanostructured metal as etching mask was applied instead of the expensive e-beam lithography. The pseudo-periodic cone-shaped nanostructures are shown in the inset of Fig 3. They have almost the same average height, pitch and base diameter as the periodic nanostructures. The same good anti-reflectance have been achieved, shown in Fig. 3. The surface reflectance was reduced from $20.5 \%$ of the bare $\mathrm{SiC}$ to $1.7 \%$ of ARS $\mathrm{SiC}$. 


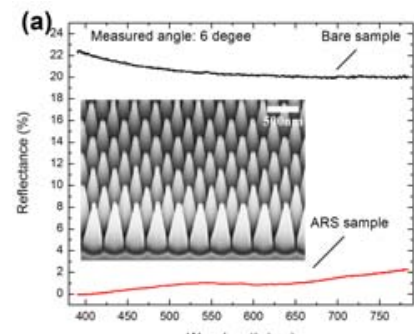

(b)
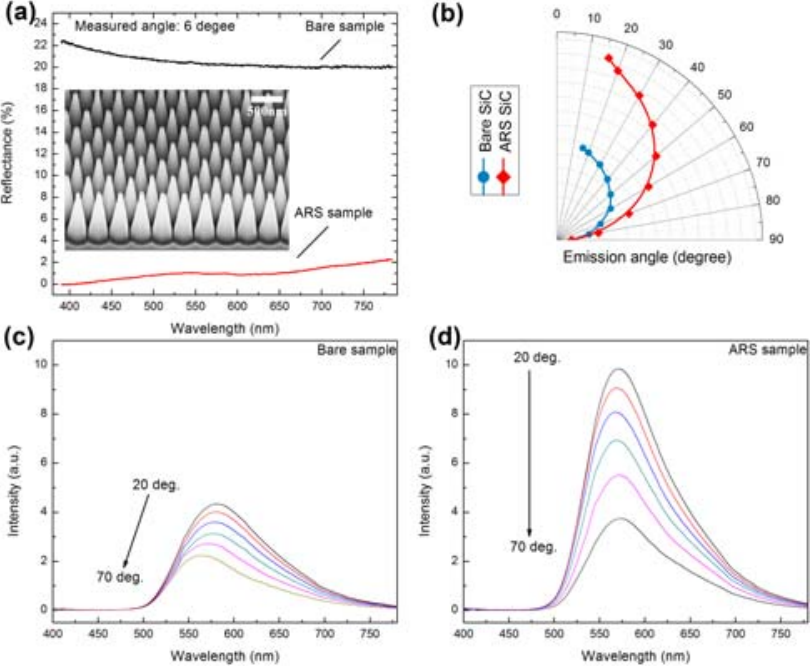

Fig. 2: (a) Surface reflectance (inset: SEM figure of fabricated ARS on SiC); (b) spatial emission pattern; angle-resolved photoluminescence of (c) bare and (d) ARS SiC samples.

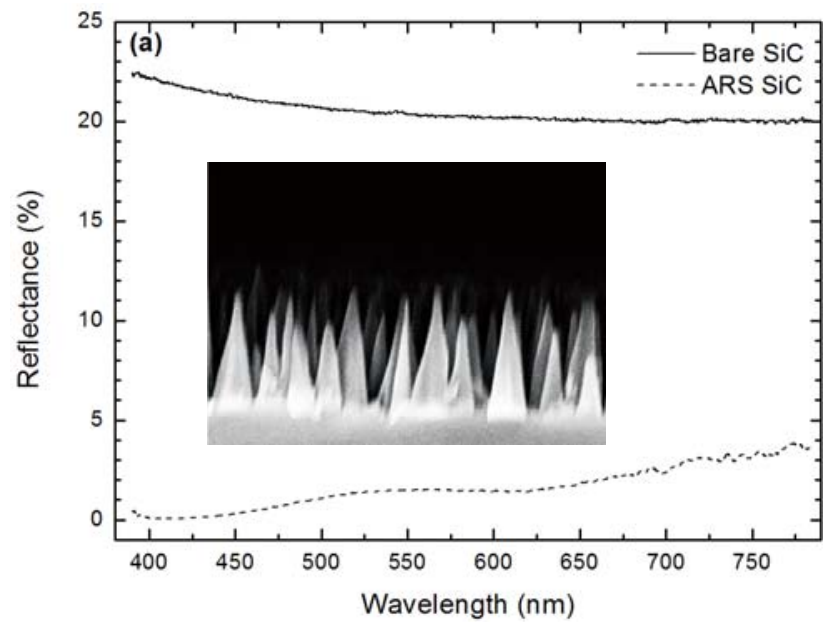

Fig. 3: Surface reflectance of bare SiC and pseudo-periodic nanostructured ARS SiC(inset: SEM figure of pseudo-periodic ARS on SiC);

\section{Conclusion}

Optimized N and B concentration for f-SiC has been found. Cone-shaped ARS structures have been fabricated and demonstrated that it is an effective way to suppress the surface reflection for the fluorescent SiC sample in the whole visible spectral range. These promising results pave the way for $\mathrm{f}-\mathrm{SiC}$ as a wavelength converter for white LEDs.

\section{Acknowledgements}

This work was supported by Danish council for strategic research (No. 09-072118), Nordic Energy Research, Swedish Research Council (project No. 2009-5307), and Bundesministerium für Bildung und Forschung (contract 03SF0393)

\section{References}

[1] S. Kamiyama, S. Kamiyama,a_ T. Maeda, Y. Nakamura,et al., “ Extremely high quantum efficiency of donor-acceptor-pair emission in Nand-B-doped 6H-SiC”, J. Appl. Phys. 99, 093108 (2006).

[2] M. Syväjärvi, J. Müller, J. W. Sun, V. Grivickas, Y. Ou, V. Jokubavicius, P. Hens, M. Kaisr, K. Ariyawong, K. Gulbinas, P. Hens, R. Liljedahl, M. K. Linnarsson, S. Kamiyama, P. Wellmann, E. Spiecker, H. Ou, "Fluorescent SiC as a new material for white LEDs” Physica Scripta 2012, 014002 (2012).

[3] Y. Ou, V. Jokubavicius, S. Kamiyama, C. Liu, R. W Berg, M. Linnarsson, R. Yakimova, M. Syväjärvi, H. Ou, “Donor-acceptor-pair emission characterization in N-B doped fluorescent SiC”, Opt. Mater. Express 1, 1439-1446 (2011). 